\title{
Ticket Fare Optimization for China's High-Speed Railway Based on Passenger Choice Behavior
}

\author{
Jinzi Zheng, ${ }^{1}$ Jun Liu, ${ }^{1}$ and David B. Clarke ${ }^{2}$ \\ ${ }^{1}$ School of Traffic and Transportation, Beijing Jiaotong University, Beijing 100044, China \\ ${ }^{2}$ University of Tennessee, Knoxville, TN, USA \\ Correspondence should be addressed to Jinzi Zheng; 10114214@bjtu.edu.cn
}

Received 28 October 2016; Accepted 5 February 2017; Published 21 February 2017

Academic Editor: Lu Zhen

Copyright (c) 2017 Jinzi Zheng et al. This is an open access article distributed under the Creative Commons Attribution License, which permits unrestricted use, distribution, and reproduction in any medium, provided the original work is properly cited.

\begin{abstract}
Although China's high-speed railway (HSR) is maturing after more than ten years of construction and development, the load factor and revenue of HSR could still be improved by optimizing the ticket fare structure. Different from the present unitary and changeless fare structure, this paper explores the application of multigrade fares to China's HSR. On the premise that only one fare grade can be offered for each origin-destination (O-D) at the same time, this paper addresses the questions of how to adjust ticket price over time to maximize the revenue. First, on the basis of piecewise pricing strategy, a ticket fare optimization model is built, which could be transformed to convex program to be solved. Then, based on the analysis of passenger arrival regularity using historical ticket data of Beijing-Shanghai HSR line, several experiments are performed using the method proposed in the paper to explore the properties of the optimal multigrade fare scheme.
\end{abstract}

\section{Introduction}

1.1. Research Background. The competition between railway passenger transportation and other modes of passenger transportation is increasingly fierce. In this situation, the present unitary and changeless fare structure gradually becomes the prevention of railway revenue increase and railway system development. Statistical data provided for 2014 by the Beijing-Shanghai High-Speed Railway (HSR) company shows that 13 percent of the trains had a load factor less than 65 percent. It has been confirmed theoretically and in practice that an advance-purchase discount based on the uncertainty and valuation of travel demand can assist in attaining efficient allocation of capacity [1]. Therefore, compared to the unitary and changeless fare structure, multigrade fare structure could increase the resource utilization rate, as a result of which the revenue of railway company will be improved.

A multigrade fare structure for China's high-speed railway is proposed in this paper. On the premise that only one fare grade can be offered for each origin-destination (O-D) pair at the same time, this paper examines how to adjust ticket price over time based on passenger choice behavior for each O-D.
1.2. Literature Review. A number of previous papers have examined aspects of the problem of dynamic pricing. Kincaid and Darling (1963) [2] laid the foundation for the study of multigrade price, building two optimization models to generate the optimal prices of each time from the aspects of whether the price is announced. Gallego and van Ryzin (1994) [3] analyzed the structural characteristics of optimal price for a single product, proving that the optimal solution of the deterministic problem is the upper bound of the stochastic problem. On this basis, Gallego and Van Ryzin (1997) [4] found the upper bound of the optimal expected revenue by analyzing the deterministic version of the problem for multiple products.

Pricing belongs to a tactical problem. On the practical level, methods are needed to dynamically decide the optimal timing of price changes. For a unique price change allowed to be either higher or lower, Feng and Gallego (1995) [5] put forward a control strategy based on a time threshold that depends on the number of unsold items. On the basis of this work, Feng and Xiao (2000) [6] expanded the approach to allow multiple price changes. In further work, Feng and Xiao (2000) [7] allowed the predetermined prices to change reversely. 
The research on dynamic pricing started late in China, where ticket price has traditionally remained changeless over decades. From the practical point of view, Shi [8] translated the optimal solution to a feasible approximate optimal solution. Zhang [9] applied maximum concave envelope theory to determine the optimal fare discount for each O-D of a train. With the application of dynamic game theory, Xu et al. [10] established a dynamic pricing model between HSR and air transportation. Yao et al. [11] analyzed the pricing strategy for HSR in Wuhan-Guangzhou corridor with the consideration of the competition between passenger rail transportation and other transport modes. Bingyi [12] developed a dynamic programming model to deal with the HSR revenue optimization problem with multitrain, multisegment, and multiclass, by considering passengers choice behavior. Wei et al. [13] constructed a bilevel programming model for the high-speed rail fare optimization problem, considering the benefit of both railway unit and passengers. Based on the operation data of high-speed railway, Li and Fu [14] studied the elasticity of demand, which is a key problem when optimizing ticket fare. Zheng and Liu [15] explored the application of multigrade fare in China's high-speed railway, which set prices separately by $\mathrm{O}-\mathrm{D}$ and by time period.

In our study, each train service is represented as a linear network with stations as nodes and arcs that connect O-D station pairs served. The multigrade fare strategy is generated to meet the demand of each O-D. The optimal ticket fare for each $\mathrm{O}-\mathrm{D}$ over time is driven by passenger demand, fluctuating within a certain range of the standard fare, either upward or downward. The remainder of the paper is organized as follows. In the next section we present a ticket fare optimization model based on piecewise pricing policy. In Section 3, we present several experiments and discuss properties of the optimal fare scheme based on computational results. The last section provides conclusions.

\section{Methodology}

2.1. Problem Definition and Notation. The notations used in this paper are as follows.

The problem we address in the paper is described as follows. The railway company, which is in a market with imperfect competition, sells tickets for a train service to passengers having different O-D itineraries in a limited time horizon (ticket-selling period). Before the ticket-selling period, the number of seats is predetermined and unchangeable, and afterwards unsold tickets have zero salvage value. One of the tactical level decisions the company has to make is determining the number of fare grades and the price of each grade for each O-D to maximize the total revenue. Gallego and van Ryzin (1994) [3] showed that the optimal price changes continuously with the time to departure and the number of seats remaining. Since it is unrealistic to adjust price all through the time, for practical purposes we apply a piecewise pricing policy, where in any interval of the ticket sale period for an O-D there is only one fare grade opened.

The transport service between a pair of consecutive stations is defined as a resource $i, i=1, \ldots, m$. The transport service between any pair of stations is defined as a product composed of one or more resource units $j, j=1, \ldots, n$. The resource-product incidence matrix $A=\left[a_{i j}\right]$ is a $0-1$ matrix, with $a_{i j}=1$ when resource $i$ is used by product $j$, and $a_{i j}=0$ otherwise. The initial capacity of resource $i$ is $C_{i}$, the number of seats on the train. The ticket-selling period is divided into several subperiods, with $T_{j}$ denoting the number of subperiods of product $j$ and $d_{j}^{t}$ denoting the time duration of subperiod $t$ of product $j$. For a given product $j$, the sum of the time span of all the subperiods $\sum_{t=1}^{T_{j}} d_{j}^{t}$ is the duration of ticket-selling period of $j$, which ends as the train departs from the origin of $j$.

Customers are usually divided into two categories, myopic and strategic [16]. Strategic customers optimize their purchase behavior according to the company pricing strategy, while myopic customers buy a product as soon as its price is less than their reservation price. The more expensive the product is, the more necessary it becomes to model strategic customers. However, there is not too much information and time for customers to make strategic decisions when purchasing railway tickets. Therefore, we assume myopic behavior in this paper.

Passenger demand is usually characterized as a Poisson process, for which demand within a certain time period is a stochastic variable. In a network formulation, the stochastic element vastly increases the complexity and difficulty of the problem. Following a frequently employed method, we use a deterministic model as an approximation of the stochastic problem. We denote $\lambda_{j}^{t}$ as demand density (amount of demand in unit time) of product $j$ in subperiod $t$. On the hypothesis of imperfect market competition, demand changes with price. Thus, the demand density is described as a function of time and price, $\lambda(t, p)$. This function is assumed to have the following properties.

(1) The demand function is continuously differentiable and strictly decreasing with $p$, that is, $d^{\prime}(p)<0$ on the feasible price set. The demand function has a unique inverse function $p(t, \lambda)$.

(2) The revenue rate is $r_{j}^{t}=\lambda_{j}^{t} p_{j}^{t}(\lambda)$, which is assumed to be continuously bounded concave.

Examples include the commonly used linear demand function $\lambda(p)=a-b p$ and the exponential demand function $\lambda(p)=a e^{-b p}$.

2.2. Modeling. Although we seek optimal prices, it is convenient to employ the demand density function $\lambda_{j}^{t}$, which is the unique inverse function of price, as the model decision variable. The ticket fare optimization model is then

$$
\max \quad R(\lambda)=\sum_{j=1}^{n} \sum_{t=1}^{T_{j}} \lambda_{j}^{t} p_{j}^{t}(\lambda) d_{j}^{t}
$$




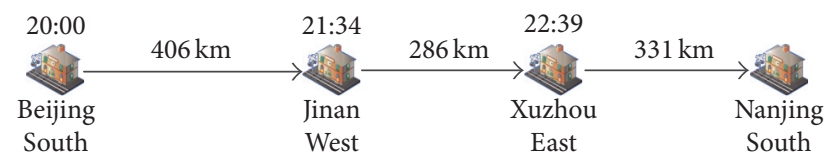

FIgURE 1: Route map of train G205.

$$
\begin{array}{ll}
\text { s.t. } & \sum_{j=1}^{n} \sum_{t=1}^{T_{j}} a_{i j} \lambda_{j}^{t} d_{j}^{t} \leq C_{i} \quad \forall i \\
& (1-\alpha) p_{j}^{0} \leq p_{j}^{t}(\lambda) \leq(1+\beta) p_{j}^{0} \quad \forall t, j .
\end{array}
$$

The objective function (1) is to maximize the total revenue produced by all the products in the whole ticket-selling period. In this paper we assume that tickets are sold on a firstcome, first-served basis. Thus the number of booking requests accepted is restrained only by the capacity of each resource, as shown in inequation (2). Inequation (3) restricts the range that the price fluctuates around the basis price, with the upper bound based on some customer psychological threshold and the lower bound the railway's transportation cost. We denote the basis price of product $j$ as $p_{j}^{0}$, the maximum downward fluctuation ratio as $\alpha$, and the maximum upward fluctuation ratio as $\beta$.

According to property 2 of the demand function, the objective function of the model is concave, and the constraints are concave, too. By introducing $f(\lambda)=-R(\lambda)$, the model above can be transformed into a convex program with the objective of minimizing $f(\lambda)$, for which the K-T point is the optimal solution of the original problem. The ticket fare optimization model ((1)-(3)) could be solved by finding the $\mathrm{K}-\mathrm{T}$ point of the new convex program.

\section{Case Study}

3.1. Case Introduction. Train G205, which has a low load factor, was the case to verify our multigrade fare strategy. The route map of G205 (Figure 1) shows that there are 3 resources in our case, $i=\{1,2,3\}=$ Beijing South-Jinan West, Jinan West-Xuzhou East, Xuzhou East-Nanjing South $\}$ and 6 products, $j=\{1,2,3,4,5,6\}=$ Beijing South-Jinan West, Beijing South-Xuzhou East, Beijing South-Nanjing South, Jinan West-Xuzhou East, Jinan West-Nanjing South, Xuzhou East-Nanjing South\}. The resource-product incidence matrix is

$$
A=\left[\begin{array}{llllll}
1 & 1 & 1 & 0 & 0 & 0 \\
0 & 1 & 1 & 1 & 1 & 0 \\
0 & 0 & 1 & 0 & 1 & 1
\end{array}\right] .
$$

Train G205 has a passenger capacity of 1005, thus the initial capacity of each resource, $C_{i}=1005, i=1,2,3$.

We employ the log-linear demand function commonly used in economics to describe the relationship between demand and price:

$$
\lambda(p)=\lambda^{0} e^{-\varepsilon^{0}\left(p / p^{0}-1\right)} .
$$

TABLE 1: Estimates for price elasticity of demand.

\begin{tabular}{lcc}
\hline O-D & Mileage $(\mathrm{km})$ & $\begin{array}{c}\text { Price elasticity of } \\
\text { demand }\end{array}$ \\
\hline Jinan West-Xuzhou East & 286 & -0.74 \\
Xuzhou East-Nanjing & 331 & -0.67 \\
South & 406 & -0.98 \\
Beijing South-Jinan West & 617 & -0.98 \\
Jinan West-Nanjing South & 692 & -1.05 \\
$\begin{array}{l}\text { Beijing South-Xuzhou East } \\
\text { Beijing South-Nanjing }\end{array}$ & 1023 & -1.21 \\
South & &
\end{tabular}

In (5), $p^{0}$ is the basis price, $\lambda^{0}$ is the demand density under the basis price, and $\varepsilon^{0}$ is the absolute value of price elasticity of demand, the negative sign of which means that demand and price are inversely correlated. The unique inverse function of (5), which is the expression of price, is

$$
p(\lambda)=\left(\frac{1}{\varepsilon^{0}} \ln \left(\frac{\lambda^{0}}{\lambda}\right)+1\right) p^{0} .
$$

The price elasticity of demand is a key parameter of the demand function, indicating the response degree of demand to a change in price. We estimated the price elasticity of demand of the O-Ds of train G205 using ticket data for the summer of 2013, when discounts were offered. The price elasticity of demand, which is the ratio of the percentage change in demand and the percentage change in price, could be calculated using the following equation, and the resulting estimates are shown in Table 1.

$$
E_{p}=\frac{\Delta \lambda / \bar{\lambda}}{\Delta p / \bar{p}}=\frac{\left(\lambda_{2}-\lambda_{1}\right) /\left(\left(\lambda_{1}+\lambda_{2}\right) / 2\right)}{\left(p_{2}-p_{1}\right) /\left(\left(p_{1}+p_{2}\right) / 2\right)} .
$$

The resulting estimates of price elasticity of demand are in conformity with the existing research results, from the aspect of competition between the high-speed railway and other transport modes $[14,16]$. The Jinan-Xuzhou, XuzhouNanjing, and Beijing-Jinan O-Ds exceed the competitive distance of highway transportation but are less than that of civil aviation. Thus the sensitivity of demand to price is weak for these O-Ds. Jinan-Nanjing and Beijing-Xuzhou are in the range where civil aviation is competitive with highspeed rail, but there is no direct flight between these city pairs, increasing air travel time, and difficulty. Since air travel is more expensive than high-speed rail, passengers mainly choose high-speed rail and the demand sensitivity to price remains weak for the two O-Ds. In comparison, Beijing to Nanjing lies within the distance range where high-speed rail and civil aviation compete, and there are direct flights between the cities. Since passengers have competing travel options, demand is more sensitive to price.

3.2. Computation Results. We apply MATLAB to solve the ticket fare optimization problem proposed above. Two experiments are performed to examine the characteristics of the 


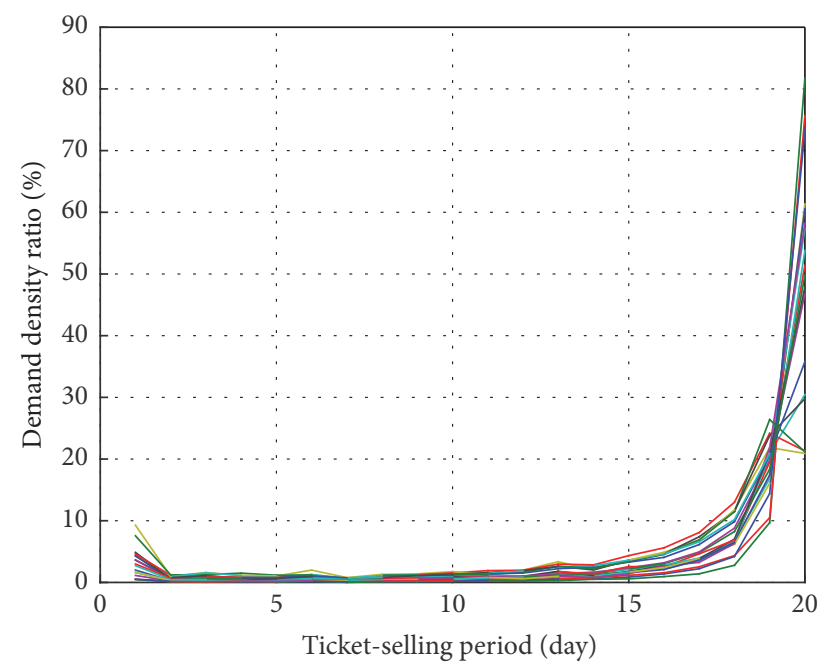

Figure 2: The demand density ratio of each day by O-D.

optimal fare scheme. The first explores the relationship between the optimal fare scheme and price elasticity of demand.

We analyze the passenger arrival regularity as the basis of the first experiment, using historical ticket data for the Beijing-Shanghai High-Speed Railway during the period March 1, 2013, to March 13, 2014. For a certain train, $\lambda_{k}^{s}$ denotes the demand density per hour for O-D $k$ on day $s$. This is the value of the number of tickets sold for O-D $k$ on day $s$ divided by the ticket-selling hours of that day. The demand density ratio of O-D $k$ on day $s, y_{k}^{s}=\left(\lambda_{k}^{s} / \sum_{s=1}^{S} \lambda_{k}^{s}\right) * 100 \%(S$ is the number of days of ticket-selling period), indicates the intensity of demand on day $s$. Averaging the value $y_{k}^{s}$ of all the trains for $k$ yields the daily demand density ratio by O-D. Figure 2 shows these results.

As Figure 2 shows, the demand density ratio increases over time except for the first day and the departure day. In the first experiment, we divide the ticket-selling period into two segments where the demand density ratio equals 5 percent. For a given O-D, the first subperiod is from the first day to the last day with demand density ratio less than or equal to $5 \%$, with the remaining days belonging to the second subperiod. Under this method, two fare grades are offered, with each subperiod having one price. The current ticket price is used as the basis price $p^{0}$, around which the maximum downward fluctuation percentage is set as $\alpha=40 \%$, and the maximum upward fluctuation percentage is $\beta=30 \%$. Table 2 provides the experiment parameters including ticket-selling hours during each subperiod $d_{j}^{t}$, the hourly demand density under the basis price $\lambda_{j}^{t, 0}$, and the basis price $p_{j}^{0}$.

It is commonly assumed that leisure travelers who are sensitive to price tend to arrive early, whereas business travelers who are not so sensitive to price arrive late. Under this hypothesis, we set the price elasticity of demand of the first subperiod as $10 \%$ higher than that of the second subperiod. The price elasticity of demand calculated from historical ticket data (see Table 1), which is deemed as 1, is the average value of that of the two subperiods. We gradually increase the
TABLE 2: Input parameters.

\begin{tabular}{cccccc}
\hline$j$ & \multicolumn{2}{c}{$t=1$} & \multicolumn{2}{c}{$t=2$} & $p_{j}^{0}$ \\
\hline 1 & $d_{j}^{t}$ & $\lambda_{j}^{t, 0}$ & $d_{j}^{t}$ & $\lambda_{j}^{t, 0}$ & \\
2 & 399 & 0.051 & 68 & 1.481 & 184.5 \\
3 & 399 & 0.051 & 68 & 0.982 & 309 \\
4 & 475 & 0.081 & 92 & 0.849 & 443.5 \\
5 & 399 & 0.004 & 45.5 & 0.376 & 129.5 \\
6 & 399 & 0.008 & 69.6 & 0.254 & 279 \\
\hline
\end{tabular}

average price elasticity at the rate of 10 percent and obtain the train revenue and load factor of the optimal fare scheme on each level of price elasticity of demand. Figure 3 displays the results.

We can see that the train revenue and load factor increase with the price elasticity of demand, which indicates that the more sensitive the demand is to price, the better the application effect of a multigrade fare strategy is. This is important in a market with a variety of competitive transportation modes.

The second experiment studies the relationship between optimal fare scheme and the number of fare grades. We determine the optimal fare schemes for two, three, and four fare grades, along with the train revenue and load. Table 3 provides these results along with the basic fare scheme.

Table 3 shows that the train revenue increases with the number of fare grades, though the load factor increase percentage declines relative to the basic fare. As Chinese railway transportation serves the public welfare, we should pursue profit on the premise of meeting passengers' travel demand as much as possible. Therefore, the three-grade fare strategy that balances train revenue and load factor is most suitable. Table 4 provides the input parameters and optimal solution of the three-grade fare strategy.

The experiments that make use of the actual data show that the multigrade fare strategy can not only increase revenue but also stimulate the potential demand, compared to the present unitary fare structure. This indicates the multigrade fare strategy is suitable for China's high-speed railway, especially in the market with fierce competition with other transportation modes. The second experiment tells that the amount of fare grades should not be too much, which was also proved in practice by the experience of Britain and France railway [17].

\section{Conclusions}

This paper explores the application of multigrade fare structure in China's HSR, where the single-grade fare strategy has always been used. Our goal is to maximize the expected revenue of a train by setting multiple ticket prices according with different valuations of passengers.

Based on a piecewise pricing strategy, we first build a ticket fare optimization model that can be transformed to a convex program to solve. Taking train G205 as a case study, we conducted two experiments to examine the properties of the optimal fare scheme. The experiment results show 


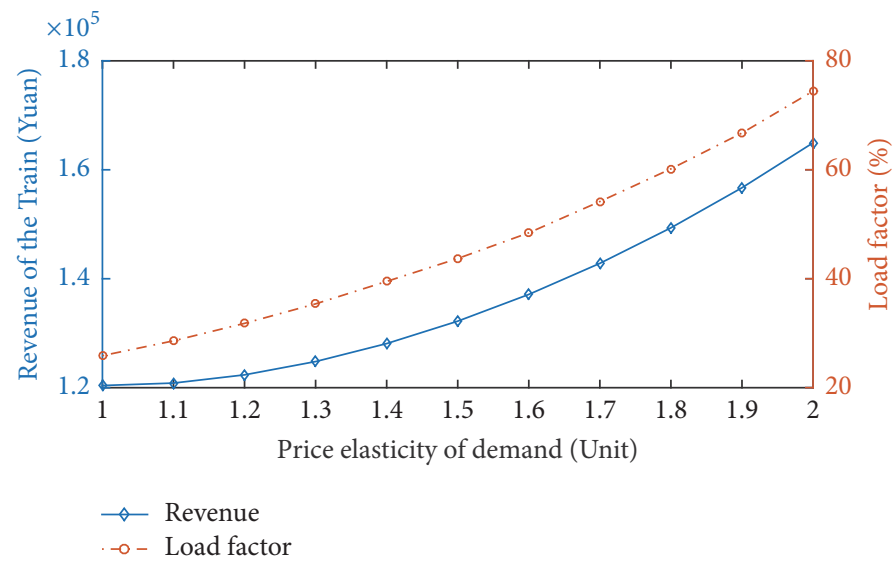

FIGURE 3: Relation between optimal fare scheme and price elasticity of demand.

TABLE 3: The relation between optimal fare scheme and number of fare grades.

\begin{tabular}{lcccc}
\hline & Revenue (Yuan) & Revenue increase pct. & Load factor & Load factor increase pct. \\
\hline Basic fare scheme & 112462.63 & & $24.67 \%$ & \\
Two fare grades & 119647.30 & $6.39 \%$ & $26.88 \%$ & $8.94 \%$ \\
Three fare grades & 119772.47 & $6.50 \%$ & $25.87 \%$ & $4.90 \%$ \\
Four fare grades & 120326.56 & $6.99 \%$ & $25.14 \%$ & $1.92 \%$ \\
\hline
\end{tabular}

TABLE 4: Parameters and optimal solution of the three-grade fare strategy.

\begin{tabular}{|c|c|c|c|c|c|c|}
\hline & $\varepsilon_{j}^{t, 0}$ & $\lambda_{j}^{t, 0}$ & $p_{j}^{0}$ & $d_{j}^{t}$ & $\lambda_{j}^{t}$ & $p_{j}^{t}$ \\
\hline$j=1 t=1$ & 1.07 & 0.029 & 184.5 & 303 & 0.031 & 172 \\
\hline$j=1 t=2$ & 0.98 & 0.122 & 184.5 & 96 & 0.120 & 188 \\
\hline$j=1 t=3$ & 0.89 & 1.481 & 184.5 & 68 & 1.327 & 207 \\
\hline$j=2 t=1$ & 1.15 & 0.033 & 309 & 231 & 0.038 & 269 \\
\hline$j=2 t=2$ & 1.05 & 0.077 & 309 & 168 & 0.081 & 294 \\
\hline$j=2 t=3$ & 0.95 & 0.982 & 309 & 68 & 0.934 & 325 \\
\hline$j=3 t=1$ & 1.33 & 0.06 & 443.5 & 183 & 0.084 & 333 \\
\hline$j=3 t=2$ & 1.21 & 0.101 & 443.5 & 192 & 0.125 & 366 \\
\hline$j=3 t=3$ & 1.10 & 0.849 & 443.5 & 92 & 0.938 & 403 \\
\hline$j=4 t=1$ & 0.81 & 0.002 & 129.5 & 375 & 0.002 & 130 \\
\hline$j=4 t=2$ & 0.74 & 0.017 & 129.5 & 48 & 0.014 & 164 \\
\hline$j=4 t=3$ & 0.67 & 0.376 & 129.5 & 45.5 & 0.307 & 168 \\
\hline$j=5 t=1$ & 1.07 & 0.005 & 279 & 327 & 0.006 & 259 \\
\hline$j=5 t=2$ & 0.98 & 0.022 & 279 & 72 & 0.022 & 284 \\
\hline$j=5 t=3$ & 0.89 & 0.254 & 279 & 69.5 & 0.228 & 314 \\
\hline$j=6 t=1$ & 0.73 & 0.022 & 149.5 & 279 & 0.018 & 190 \\
\hline$j=6 t=2$ & 0.67 & 0.075 & 149.5 & 120 & 0.061 & 192 \\
\hline$j=6 t=3$ & 0.61 & 0.943 & 149.5 & 70.6 & 0.786 & 194 \\
\hline
\end{tabular}

that the more sensitive the demand is to price, the better the application effect of the multigrade fare strategy is. By comparing the optimal solutions of different fare schemes with the basic fare strategy, we find that multigrade fare strategy can increase both the train revenue and load factor. This indicates that multigrade fare is suitable for China's HSR. At last we give a suggestion about determining the most suitable multigrade fare scheme. Since China's railway is a seminonprofit organization that should pursue benefit on the premise of meeting passengers' travel demand as much as possible, we recommend that a three-grade fare scheme that balances train revenue and load factor is the most suitable.

There are certainly many possible directions for future research in this area. In this paper, the passenger behavior 
is assumed to be deterministic, and the demand quantity is assumed to be fixed. Being more realistic, in the future research we should consider the passengers' response to ticket fare optimization, and the demand quantity should be regarded as elastic. Another direction is to expand our study to the system with multiple trains. Because the ticket fare adjustment of some train would cause the transfer of passengers between the trains that provide the same O-D transportation service, we should further research how to collaboratively optimize the ticket fare of these trains.

\section{Notations}

$\begin{array}{ll}i: & \text { Symbol of source, } i=1, \ldots, m \\ j: & \text { Symbol of product, } j=1, \ldots, n \\ C_{i}: & \text { Initial capacity of resource } i \\ \lambda_{j}^{t}: & \text { Demand density of product } j \text { in subperiod } t \\ d_{j}^{t}: & \text { Time duration of subperiod } t \text { of product } j \\ p_{j}^{t}: & \text { Price of product } j \text { in subperiod } t \\ r_{j}^{t}: & \text { Revenue rate of product } j \text { in subperiod } t \\ p_{j}^{0}: & \text { Basis price of product } j \\ T_{j}: & \text { The number of ticket-selling subperiods } \\ A=\left[a_{i j}\right]: & \text { Resource-product incidence matrix } \\ \alpha: & \text { Maximum downward fluctuation ratio of price } \\ \beta: & \text { Maximum upward fluctuation ratio of price. }\end{array}$

\section{Competing Interests}

The authors declare that they have no competing interests.

\section{Acknowledgments}

This research was supported by China Railway Corporation Technology Research and Development Plan Project (2016X005-E).

\section{References}

[1] I. L. Gale and T. J. Holmes, "The efficiency of advance-purchase discounts in the presence of aggregate demand uncertainty," International Journal of Industrial Organization, vol. 10, no. 3, pp. 413-437, 1992.

[2] W. M. Kincaid and D. A. Darling, "An inventory pricing problem," Journal of Mathematical Analysis and Applications, vol. 7, pp. 183-208, 1963.

[3] G. Gallego and G. van Ryzin, "Optimal dynamic pricing of inventories with stochastic demand over finite horizons," Management Science, vol. 40, no. 8, pp. 999-1020, 1994.

[4] G. Gallego and G. Van Ryzin, "A multiproduct dynamic pricing problem and its applications to network yield management," Operations Research, vol. 45, no. 1, pp. 24-41, 1997.

[5] Y. Feng and G. Gallego, "Optimal starting times for end-ofseason sales and optimal stopping times for promotional fares," Management Science, vol. 41, no. 8, pp. 1371-1391, 1995.

[6] Y. Feng and B. Xiao, "Optimal policies of yield management with multiple predetermined prices," Operations Research, vol. 48, no. 2, pp. 332-343, 2000.
[7] Y. Feng and B. Xiao, "Continuous-time yield management model with multiple prices and reversible price changes," Management Science, vol. 46, no. 5, pp. 644-657, 2000.

[8] F. Shi, "Optimal dynamic pricing of railway passenger ticket," Journal of the China Railway Society, vol. 24, no. 1, pp. 1-4, 2002.

[9] X. Zhang, The Research on Railway Tickets Discount Sales in China, Southwest Jiaotong University, Chengdu, China, 2005.

[10] Z. Xu, L. Weixin, C. Quande, and Z. Bingru, "Research on dynamic pricing between high speed rail and air transport under the influence of induced passenger flow," Information Technology Journal, vol. 11, no. 4, pp. 431-435, 2012.

[11] E. Yao, Q. Yang, Y. Zhang, and X. Sun, "A study on highspeed rail pricing strategy in the context of modes competition," Discrete Dynamics in Nature and Society, vol. 2013, Article ID 715256, 6 pages, 2013.

[12] Q. Bingyi, Research on Revenue Management for Dedicated Passenger Line Based on Passenger Choice Behavior, Southwest Jiaotong Universiy, Chengdu, China, 2014.

[13] L. Wei, H. Chen, J. Jiang, H. Wang, and H. Shao, "Study on bi-level programming model of high-speed rail fares based on generalized cost function," Journal of Railway Science and Engineering, vol. 12, no. 2, pp. 250-256, 2015.

[14] W. Li and Z. Fu, "Elasticity analysis for high-speed railway passenger transport demand," Journal of Railway Science and Engineering, vol. 13, no. 11, pp. 2115-2124, 2016.

[15] J. Zheng and J. Liu, "The research on ticket fare optimization for China's high-speed train," Mathematical Problems in Engineering, vol. 2016, Article ID 5073053, 8 pages, 2016.

[16] K. T. Talluri and G. J. Van Ryzin, The Theory and Practice of Revenue Management, Springer, Boston, Mass, USA, 2005.

[17] M. Huang, Research on Comparative Advantage and Rational Application Range of Expressway Passenger Transportation, Changan University, Xi’an, China, 2004. 


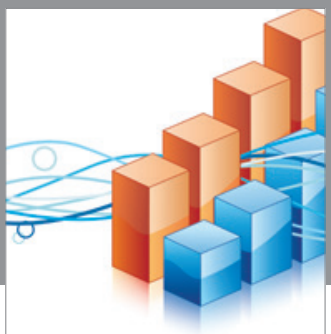

Advances in

Operations Research

vatem alat4

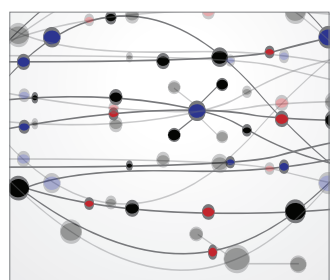

\section{The Scientific} World Journal
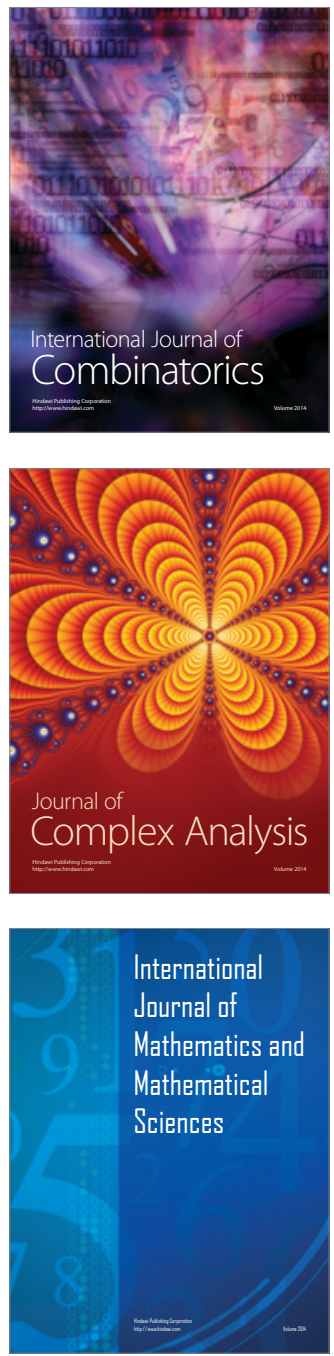
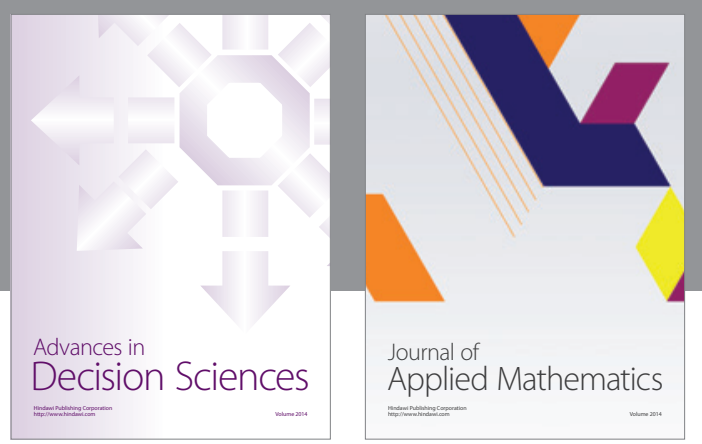

Algebra

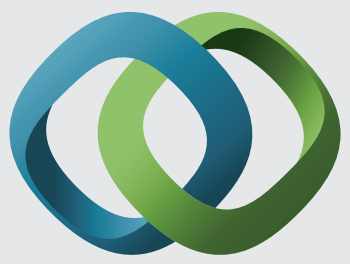

\section{Hindawi}

Submit your manuscripts at

https://www.hindawi.com
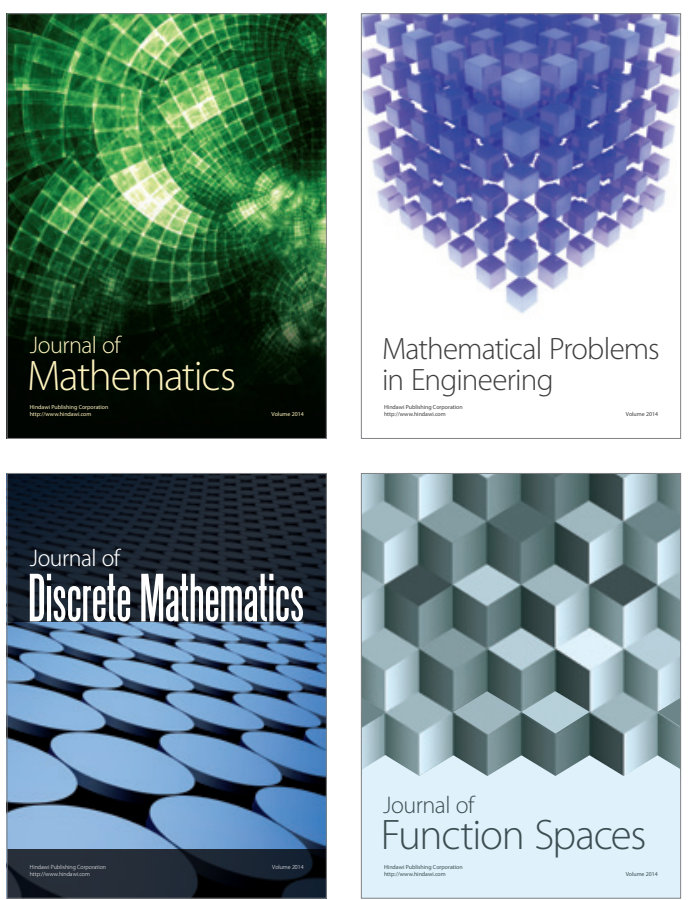

Mathematical Problems in Engineering
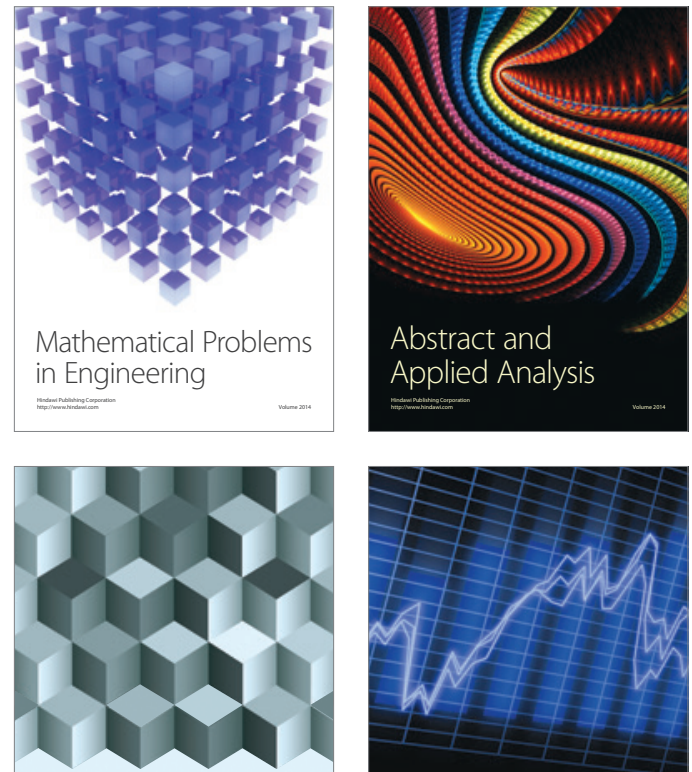

Journal of

Function Spaces

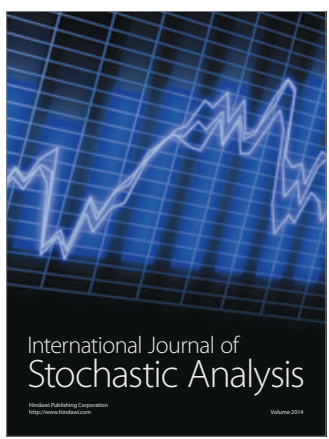

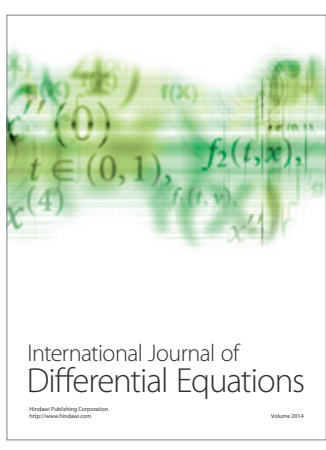
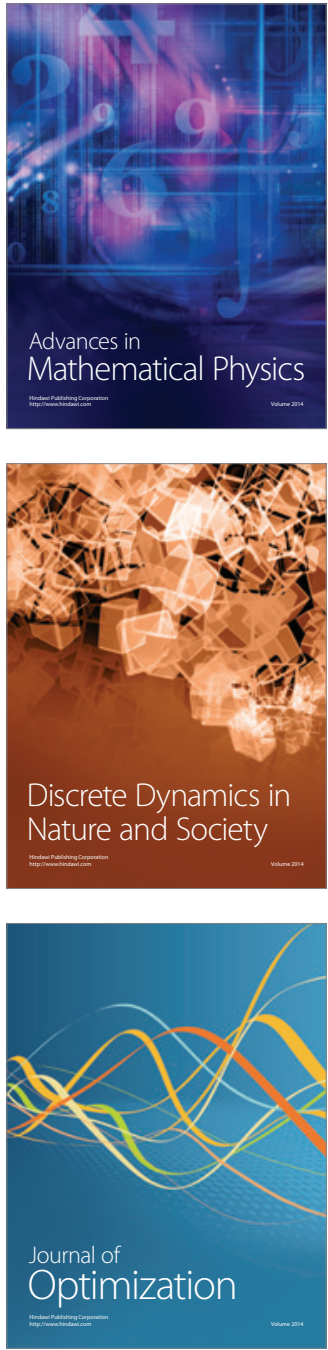